\title{
La comunicación comunitaria: una plataforma para la movilización social y la lucha por los derechos*
}

\author{
DOI: https://doi.org/10.18046/recs.i33.3916
}

The Community Communication: A Platform for the Social
Mobilization and the Defense of the Human Rights

Julián Camilo Giraldo-Naranjo ${ }^{* *}$

Corporación Universitaria Remington (Medellín, Colombia)

\footnotetext{
* Artículo que presenta parte de los resultados del proyecto de investigación: "En la periferia se reivindica el derecho al territorio: movilización y resistencia desde la Comuna 8 de Medellín". Fue financiado con recursos de la Vicerrectoría de Investigaciones de la Corporación Universitaria Remington (Colombia). Artículo de investigación recibido el 24.02.2020 y aceptado el 03.01.2021.

** Comunicador y relacionista corporativo. Magister en Derecho y estudiante del Doctorado en Derecho de la Universidad de Antioquia (Colombia). Profesor de tiempo completo de la Corporación Universitaria Remington (Colombia) y de cátedra de la Universidad de Antioquia (Colombia). Miembro del grupo de investigación GIFICUR. Correo:julian-1829@ hotmail.com ORCID: https://orcid.org/0000-0003-3895-382X
} 


\section{Cómo citar/How to cite}

Giraldo-Naranjo, Julián Camilo (2021). La comunicación comunitaria: una plataforma para la movilización social y la lucha por los derechos. Revista CS, 33, 171-204. https:// doi.org/10.18046/recs.i33.3916 


\section{Resumen}

Este artículo presenta la experiencia de la Corporación para la Comunicación Ciudad Comuna y su trabajo en la Comuna 8 de Medellín durante el período 2012-2015, como un caso representativo en el que los habitantes de este espacio local, afectados por las intervenciones en sus territorios urbanos, se reivindicaron como comunicadores populares -sujetos políticos y de derechos- que emplearon diferentes medios y herramientas, como la educación, la reportería visual y escrita, el video social participativo y otras acciones, para representar otras formas de concebir la vida en los barrios populares y disputarse los sentidos sobre los derechos. El estudio concluye que, mediante el ejercicio crítico de la comunicación comunitaria, enfocados en su poder trasformador, se crearon sentidos comunes sobre una racionalidad emancipatoria del derecho, en donde se reclamó la ciudad, el territorio, la memoria y la paz como los principales derechos necesarios para vivir con dignidad en los barrios populares.

\section{PALABRAS CLAVE:}

resistencia, comunicación popular, derecho, Medellín

This paper presents the experience of the Corporación para la Comunicación Ciudad Comuna and its work in the neighborhoods of the Commune 8 of Medellin during the 2012-2015 period. This is a representative case where the people from the local space, affected by the urban transformations, claimed themselves as subjects of rights and communicators that used different tools, such as: education, visual and written reporting, social video, and other actions, in order to show other ways of conceiving a dignified life in the marginal neighborhoods, and dispute the senses of rights. The study concludes that, through a critical exercise of community communication and its potential as a transformative power, common senses were created on an emancipatory rationality of the rights, where the subjects from the Commune claimed the city, territory, memory, and peace, as the fundamental rights to live with dignity in the marginal neighborhoods.

\section{KEYWORDS:}

Resistance, Community Communication, Right, Medellín 



\section{Introducción: el contexto de transformación y resistencia en Medellín}

La transformación acelerada de Medellín durante la primera parte del siglo XIX inició con la concentración de las actividades políticas, religiosas, comerciales y administrativas de la provincia de Antioquia (González, 2007), y se materializó de forma concreta, al final de ese siglo, con el impulso de las producciones minero-cafeteras de la región (Nieto, 2013) y, durante las primeras décadas del XX, con el advenimiento de la ciudad industrial de Colombia (Álvarez, 1996; Betancur, 2001; Mayor-Mora, 1989).

En las últimas décadas del siglo XX, los cambios en el modo de producción capitalista a nivel mundial tuvieron eco en el contexto local con el degaste del modelo industrial y, como consecuencia, el aumento del desempleo y la alerta, desde los sectores prestantes de la sociedad antioqueña, con discursos de odio sobre los nuevos habitantes, a causa de la inversión de los valores tradicionales que caracterizaban el ethos empresarial del nacido en la región (Franco, 2006). El crecimiento de la violencia en la ciudad y la escalada del conflicto armado colombiano trajeron, como algunas de sus consecuencias, flujos migratorios que ocasionaron el poblamiento irregular de la periferia de la ciudad, la lucha de personas de diferente origen por encontrar un lugar donde habitar, en donde la ciudad autoconstruida se convirtió en sueño, pero también en desesperanza y, en todo caso, privilegiada desde su valor de uso (Capron; González-Arellano, 2006; Giraldo, 2017; Harvey, 2014; Roy, 2013).

En cierta ocasión, Raúl Zibechi (2015), en un acercamiento con las comunidades urbano-populares de Medellín, realizó una afirmación contundente-cercana a una de las máximas expuestas por la geografía social y crítica respecto al desarrollo geográfico desigual del modelo capitalista-: "los más pobres viven en las comunas más alejadas del centro. Los más cercanos a las cumbres fueron los últimos en llegar. Esa es la historia de la 'ladera que resiste y construye en Medellín'" (Zibechi, 2015: 39). En otras palabras, aseguró que en Medellín las clases se encuentran definidas por la geografía.

En la década de 1990, la crisis de gobernabilidad de Medellín fue significativa: alcanzó la mayor tasa de homicidios a nivel mundial (Sierra, 2016) y la ciudad fue reconocida, en el contexto internacional, por el papel que desempeñaba como centro del cartel de droga más nombrado del mundo. De acuerdo con Dávila (2016: 116), se pueden evidenciar 5 períodos de la dinámica de la violencia en Medellín; a saber: 1) narcotráfico y sicariato $(1985-1991) ; 2)$ milicias y bandas antes de los procesos de negociación (1991-1994);3) recomposición de la presencia paramilitar y guerrillera en la ciudad (1995-2005); 4) fracasos de los procesos de paz con las 
Autodefensas Unidas de Colombia (2005-2008), y 5) recomposición de estructuras criminales (2008-2013).

En consonancia con Dávila (2016), en torno a las investigaciones sobre este tema se presenta una situación paradójica, puesto que, aunque en los últimos 25 años las cifras de muertos violentos se han reducido, han incrementado el interés y las publicaciones académicas sobre esta cuestión. Caso similar sucede con los contenidos mediáticos sobre la violencia, cuyo foco ha crecido por parte de producciones locales y extranjeras. En ambos escenarios, la vida en los barrios populares ha sido definida en términos de caos, en donde opera la ley del más fuerte, y donde se presenta una especie de suspensión del orden legal y constitucional (Lemaitre, 2011). Parafraseando a Serje (2017), desde el discurso se ha invisibilizado a los habitantes tradicionales de los barrios populares, se populariza una idea de emergencia-que en muchas ocasiones legitima la intervención a través de la fuerza pública- y se muestra la excepción como la regla.

El papel de los mandatarios locales, desde finales de la década del noventa, para tratar de cambiar la idea de la ciudad violenta en el imaginario colectivo, fue la de implementar una serie de obras urbanas que se enfocaron en mostrar una cara diferente de la ciudad, aunque muchos de estos cambios no trascendieron una mera intervención cosmética. El trabajo de Franco, cuyo título es lo suficientemente sugerente Medellín: orden, desigualdad, fragilidad, muestra claramente lo que significó el fortalecimiento de un supuesto modelo Medellín, cuyas bases se soportaron en la "transformación empresarial del gobierno urbano" (2011:12) que tuvo como uno de sus pilares la gestión de la apariencia externa de los espacios como uno de los medios para mostrarse competitiva y atractiva para el mercado internacional, pero que, de igual manera, escondía el flagelo de mucha de su gente que, entre muchas problemáticas, se veía afectada por el despojo en sus territorios, la pobreza y la desigualdad.

De acuerdo con esta orientación, trabajos como los de Kavilando y Redipaz (2018); Echeverría, Moreno, González, Mesa y Urrego (2016); Samper, Ortiz y Soto (2014), y Giraldo (2020), entre otros, han sido significativos para mostrar las víctimas de lo que ha sido considerado el desarrollo en Medellín, el lado oscuro de los macroproyectos urbanos, las rupturas en el hábitat popular, la violación de los derechos fundamentales de las comunidades pobres a causa de las obras públicas y la forma como la internacionalización de la ciudad ha respondido más a los intereses de públicos extranjeros que a los de los habitantes locales. Las administraciones municipales de Luis Pérez (2001-2003), Sergio Fajardo (2004-2007), Alonso Salazar (2008-2011) y Aníbal Gaviria (2012-2015), mediante estrategias como las denominadas "Urbanismo social", reinterpretada con el último mandatario mencionado como "Urbanismo cívico-pedagógico", privilegiaron la creación de nuevas obras que tributaron a los 
indicadores de espacio público por habitante y circuitos de transporte, entre otros, enfocadas en la transformación exterior de los espacios, pero débiles frente al cambio de la realidad social de los más pobres.

Desde la comunicación, también se han presentado trabajos importantes, como los de Krohling, Tufte y Vega (2011), así como los textos de Garcés y Jiménez (2016), y Garcés (2016), que han mostrado el uso dado por los colectivos populares para la movilización y el cambio social en el marco de las transformaciones de ciudad. De igual manera, otras investigaciones como la desarrollada por Garcés y Jiménez (2017), muestran la resistencia de las comunidades populares a través de los medios comunitarios para construir cartografias vitales y luchar por el derecho a la ciudad. Otros estudios, como los de León (1998), Kaplún (1985), Parra-Orozco (2009), Mata (2011;2016) y Martín-Barbero (1987), entre otros, aportan elementos comprensivos para entender el papel de la comunicación popular, comunitaria, y los medios alternativos y emergentes en el trabajo de creación de una consciencia sobre los derechos fundamentales de las personas. En este orden de ideas, el camino trazado por estas investigaciones vislumbra la necesidad de seguir pensando en las relaciones existentes entre derecho, comunicación, cultura y política, más allá del análisis del ejercicio de la democracia a través de los mecanismos formales de participación ciudadana, y la descripción y desarrollo dogmático de los derechos contenidos en el Artículo 20 de la Constitución colombiana de 1991, como son: la libertad de expresión, y el derecho a recibir y proporcionar información veraz y a fundar medios de comunicación.

De acuerdo con lo anterior, si se acepta, tal como lo concibió Bourdieu (2002), que los medios masivos de comunicación han ocupado un papel preponderante en la lucha simbólica por "hacer ver y hacer creer", y que las imágenes que se observan en los medios de alto consumo nacional sobre el derecho regularmente están plagadas de populismo punitivo (Velandia, 2018), caricaturas judiciales llenas de relatos amarillistas que venden la tragedia humana como objeto del espectáculo y otras historias que difícilmente cumplen la función de educar a la población sobre sus derechos, es pertinente resaltar otras formas de usar la comunicación desde dinámicas locales no ligadas a los medios tradicionales, que le podrían dar vida a luchas simbólicas por definir el derecho desde nuevas comprensiones y desde formas diversas de interpretar sus medios y fines, partiendo de un contexto local, pero interconectado a un mundo global (Santos, 2005), como ya ha sido abordado por parte de valiosos trabajos relacionados con la comunicación alternativa (Grinberg, 1981; Montero; Domínguez, 2020).

Sumado a lo anterior, es relevante que estos medios respondan a algunas preguntas, como, desde los medios comunitarios, qué usos alternativos o estratégicos se le 
dan o se le podrían dar al derecho estatal, desde la mirada de los desposeídos (Souza, 2001); de qué forma, por parte de las comunidades urbanas y mediante la comunicación, se resiste al derecho, inclusive, sin necesidad de salir de su mismo lenguaje (Fitzpatrick, 2011); cuáles son las interrelaciones entre derecho-violencia y Estado (Ruíz, 2016), más allá de la noción de fuerza organizada y el carácter coercitivo del derecho, es decir, las formas de violencia simbólica y física (Lemaitre, 2009) que se ejercen desde el derecho y que son objeto de denuncias por parte de las comunidades urbanas empleando nuevas tecnologías de la información y comunicación, pero que no representan importancia para los medios masivos; entre otros interrogantes que dan cuenta de un papel más preponderante de la comunicación y los comunicadores en la tarea de generar representaciones sobre lo que es el derecho.

Teniendo en cuenta lo anterior, en este artículo se expone una parte de los resultados de una investigación donde se analizó un proceso de resistencia en Medellín, dirigido a la reivindicación del derecho al territorio. De forma concreta, en este escrito se presenta la experiencia de resistencia de la Corporación para la Comunicación Ciudad Comuna (2012-2015), como un caso significativo en la historia de la ciudad, en donde las comunidades urbanas, mediante la comunicación comunitaria, denunciaron las mentiras del modelo de ciudad que se exponía ante el exterior; mostraron, a través de diferentes expresiones, cómo se han construido y diseñado los barrios populares, y empoderaron a las poblaciones de los bordes urbano-rurales de Medellín, no como receptores pasivos de normas jurídicas que les mandan, permiten o prohíben realizar determinadas conductas, sino todo lo contrario, como responsables de realizar transformaciones sociales donde el derecho ocupa un espacio importante, pero en referencia a un derecho contrahegemónico (Santos, 2019).

En la Comuna 8 (Villa Hermosa), durante el tiempo que se desarrolló esta investigación, se generaron intervenciones sustanciales sobre las dinámicas de los barrios que la conformaban. La administración municipal consolidó alianzas entre élites políticas, medios masivos tradicionales y empresarios, entre otros ${ }^{1}$, para la difusión de una imagen alejada, en sentido estricto, de la realidad de la ciudad. El enfoque de desarrollo y ordenamiento territorial que se buscaba consolidar estaba basado en la construcción de una ciudad integrada al centro y sus servicios (Alcaldía de Medellín, 2015; Alcaldía de Medellín; Área Metropolitana Valle de Aburrá; Centro de Estudios Urbanos y Ambientales, 2011), incluyendo varias obras en los bordes de la ciudad para frenar la expansión urbana, lo cual puso en riesgo la existencia de algunos

1. Dentro de los que se resaltan, se encuentran el Banco Interamericano de Desarrollo (BID), la Agencia de Cooperación de Estados Unidos (USAID), la Organización de Naciones Unidas (ONU); Estados como España, Reino Unido, Corea del Sur, Singapur; y empresarios nacionales e internacionales, entre otros (Alcaldía de Medellín, 2015: 128). 
barrios informales, y se amenazó con un posible redesplazamiento por causa de las obras públicas (Kavilando; Redipaz, 2018; Personería de Medellín, 2015). Esto deja en evidencia a las víctimas detrás del desarrollo de la ciudad y a aquellas personas que, aunque formalmente son sujetos de derechos humanos, en la práctica no terminan siendo más que, parafraseando a Santos (2014), un objeto de este discurso.

Durante este período, también se hizo la revisión a corto plazo del Plan de Ordenamiento Territorial (POT); además, y después de una campaña mediática liderada por la administración, se concedió a la ciudad, en 2013, el galardón a la ciudad más innovadora del mundo, y se celebró el $7^{\circ}$ Foro Urbano Mundial de la ONU (WUF7, por sus siglas en inglés), como antesala de las discusiones sobre la agenda posterior a los objetivos del milenio de desarrollo sostenible y la conferencia Hábitat III, celebrada en el año 2016 en Ecuador (Torres-Tovar, 2014).

Como estructura del artículo, en la primera parte se explica el papel del derecho en el problema abordado; continúa con la explicación de la metodología implementada para la investigación; luego, se presentan los hallazgos encontrados basados en la experiencia de Ciudad Comuna, y se finaliza con algunas conclusiones.

\section{El papel del derecho desde el problema abordado}

Desde las posturas jurídicas clásicas, se ha definido al derecho como un orden normativo que tiene la capacidad de regular la conducta humana, que se diferencia de otros, como la moral o las reglas de trato social, por su carácter coercitivo (Kelsen, 2009). Además de esto, en los sistemas jurídicos contemporáneos, ha sido influyente la postura hartiana, según la cual el derecho no solo está conformado por reglas de conducta respaldadas por algún tipo de sanciones, sino que se suman las reglas que regulan su propia producción normativa (Hart, 2004). En todo caso, desde ambas posiciones se tiende a delimitar el derecho como aquel que es puesto por una autoridad con competencia y que respeta los procedimientos previamente definidos.

Empero, la comprensión e identificación del derecho en el contexto actual es más difícil cuando se reconoce que, en los presentes Estados constitucionales de derecho (Ferrajoli, 2018), existe un grado amplio de indeterminación del derecho vigente, si se tienen en cuenta fenómenos como la positivización de una amplia gama de derechos fundamentales en las cartas políticas de los Estados, y principios constitucionales con un alto grado de generalidad y que, enfrentados entre sí, deben ser resueltos mediante mecanismos como la ponderación, el reconocimiento de cláusulas de derechos innominados en las cartas políticas y la emergencia de nuevos derechos que son fruto de reivindicaciones sociales logradas a través de mecanismos de presión 
política que trascienden las discusiones internas de la disciplina jurídica. Además, esta indeterminación se ve reforzada por la atomización del concepto de soberanía estatal y, en general, por los fenómenos de la globalización caracterizados por la interacción y tensión entre agentes económicos, representantes de los Estados, organizaciones no gubernamentales, movimientos sociales y una amplia gama de actores que, desde abajo, tejen redes solidarias para proteger los derechos y bienes fundamentales como son la ciudad, los territorios campesinos e indígenas, la naturaleza ${ }^{2}$, entre otros (Capella, 2008; Harvey, 2013; Santos; Rodríguez, 2007; Sassen, 2015).

Si bien la dimensión del derecho centrada en criterios de existencia y validez jurídica es supremamente relevante, es importante considerar que, desde una comprensión social, cultural y política como la que se privilegia en este trabajo, se reconoce que, además de la dimensión normativa del derecho (que es una de sus partes, no su todo), este es un campo de poder en el que intervienen tanto las imágenes que se crean en torno a él como las prácticas que derivan de ellas (García-Villegas, 2014). De igual manera, desde un punto de vista sociológico, como lo establece Santos (2009: 51), "las sociedades contemporáneas son jurídica y judicialmente plurales", lo que es una advertencia de que el Estado-nación no tiene la exclusividad en la producción del derecho, como ha sido defendido por la concepción político-ideológica del positivismo jurídico.

Otras construcciones jurídicas, como las que se pueden hallar en los territorios populares de las ciudades, en los cabildos indígenas, en las comunidades interrelacionadas con grupos armados, entre otras, aportan comprensiones de juridicidades alternativas que se pueden hallar intricadas entre sí por relaciones de complementariedad, oposición o dependencia. En Colombia, en particular, estas se materializan a través de tensiones marcadas entre lo oficial/no-oficial, formal/informal, monocultural/multicultural, cívico/armado, entre otras (Santos, 2009: 51 y ss.).

2. Verbigracia, la Constitución de Ecuador (2008) brinda un lugar especial a la naturaleza como sujeto de derechos y la de Bolivia (2009) reconoce la diversidad de los pueblos indígenas que habitan el Estado, ambos procesos constituyentes se consideraron como la Refundación del Estado en el continente (Santos, 2010). En Colombia, por vía de desarrollo jurisprudencial después de la sentencia hito que declaró al río Atrato como sujeto de derechos (Sentencia T-622-16 de la Corte Constitucional), se ha reconocido la subjetividad jurídica a otras entidades como la Amazonia (Sentencia STC4360-2018 de la Corte Suprema de Justicia), el río Cauca (Sentencia 38-2019 del Tribunal Superior de Medellín) y, recientemente, el 18 de noviembre de 2020, al Valle del Cocora, por parte del Tribunal Superior del Distrito Judicial de Armenia. Estos acontecimientos han sido precedidos por una fuerte presión ciudadana que, a través de diferentes expresiones organizativas y el empleo de mecanismos como el litigio estratégico y otras herramientas políticas, ha logrado que algunas de sus reivindicaciones se materialicen en un instrumento de derecho positivo. Los reclamos populares por derechos trascienden la disputa jurídica y llevan al escenario político la pelea por la garantía judicial y el cumplimiento de sus conquistas. Para profundizar en estos temas, así como en la lucha política por el derecho, se puede consultar a Langford, Rodríguez y Rossi (2017). 
De acuerdo con esto, el derecho no solo debe ser visto como un orden directivo de la conducta humana en pro de la convivencia pacífica, sino que es un campo de representaciones que normaliza estados de cosas, que crea sentidos que pueden ser aceptados, rechazados o resistidos, y es también una herramienta utilizada por los desposeídos en contra de lo considerado hegemónico.

Por tanto, son diversas las posibilidades que existen, desde la comunicación, para crear representaciones en la disputa simbólica por definir qué es el derecho, cuáles son sus posibilidades emancipatorias y el alcance de los derechos. La comunicación se convierte en una herramienta potente para posicionar, en contextos específicos imaginarios hegemónicos o contrahegemónicas del derecho (Santos, 2005), pero también para movilizar sentidos comunes en torno a la lucha política por el derecho. De acuerdo con esto, el derecho no goza de una autonomía absoluta respecto de lo social, es un campo en disputa (Bourdieu, 200o) donde compiten diferentes racionalidades, prácticas y respuestas de los agentes, dependiendo de su pertenencia a determinada consciencia jurídica y, en igual sentido, enfrenta argumentaciones e intereses, lo que es un reflejo de la lucha simbólica por materializar lo que es el derecho y las imágenes que de ahí se derivan.

De esta manera, se puede identificar un papel relevante de la comunicación como vehículo para la apropiación de un concepto específico de derecho, el cual podría ser visto tanto como un orden que defiende lo instituido y limita las posibilidades de lucha política (como en el discurso de muchos medios masivos de comunicación) o como un complejo entramado de herramientas que permite la defensa de los atropellos mediante mecanismos formales (verbigracia, acciones constitucionales como la acción de tutela, popular, de cumplimiento, entre otras) o informales (diversas acciones colectivas en las que se emplea el discurso de los derechos de las comunidades como bandera).

Para el caso particular de la lucha por los derechos en Medellín y, en especial, la alusión directa al derecho a la ciudad y su apropiación mediante la comunicación comunitaria y popular que se hace en este trabajo, cabe resaltar que este derecho, más allá de lo propuesto por Lefebvre (1978) y partiendo de Harvey (2013), no es un concepto en abstracto o definible genéricamente, todo lo contrario, es vacío y depende concretamente de las necesidades y las voces de socorro que lanzan los habitantes de las ciudades afectados por la expansión del capital. En este orden de ideas, el derecho a la ciudad puede congregar una serie de demandas y derechos prestacionales y colectivos como lo son el techo, los servicios públicos domiciliarios, el trabajo y el medio ambiente sano, pero en especial implica que 
quienes construyen y mantienen la vida urbana tienen un derecho primordial a lo que ha producido, y que una de sus reivindicaciones es el derecho inalienable a adecuar la ciudad a sus deseos más íntimos, llegaremos a una política de lo urbano que tenga sentido. (Harvey, 2013: 14)

Para finalizar, la pregunta que surge y a la que se le tratará de dar respuesta en este escrito es: más allá de las dinámicas ligadas a medios masivos, ¿qué sentidos sobre el derecho se podrían construir desde el trabajo comunitario y el empleo de la comunicación en un contexto local delimitado?

\section{Metodología}

La investigación planteada es de corte cualitativo, lo que implicó enfatizar en las subjetividades, las vivencias, la interacción entre sujetos y las representaciones de los procesos sociales (Galeano, 2012: 20-21). Se emplearon categorías empírico-analíticas como marco de comprensión del problema, y el enfoque empleado fue crítico, lo que posibilitó partir de ciertas construcciones teóricas desde su praxis emancipadora y estableciendo constantes diálogos con la realidad; en igual medida, el trabajo empírico aportó un acumulado de experiencias útiles para abordar problemas similares.

Como herramienta metodológica de investigación -lo que responde a lo general del trabajo-, se eligió el estudio de caso, combinado con la observación participante. Para la elaboración de este segmento, se realizó una delimitación de las características del caso concreto y se estableció un programa de observaciones en donde el investigador acompañó al colectivo de Ciudad Comuna en el desarrollo de algunos de sus procesos, como fueron: actividades de cartografía social, recorridos territoriales y movilizaciones, toma de fotografías del Colectivo de Escuela de Comunicación y la proyección de algunas de sus producciones. Del ejercicio de observación, como lo reconoce Tailor y Bogdan (1992), surgieron los patrones para analizar el resto de información recolectada.

Como técnica de investigación, se empleó el análisis documental. Además de la revisión de trabajos teóricos y lecturas de segunda mano sobre el tema, las fuentes primarias objeto de revisión fueron las siguientes: las publicaciones realizadas entre 2012 y 2015 por parte del periódico comunitario de Ciudad Comuna (Visión 8), los videos publicados en el canal de YouTube por parte del colectivo audiovisual de la corporación (Común audiovisual), la revisión de las publicaciones de la página web y de redes sociales (Facebook y Flickr).

En los Cuadros 1 y 2 se hace una relación entre las ediciones del periódico comunitario Visión 8 y las producciones audiovisuales creadas por miembros de la comuna 


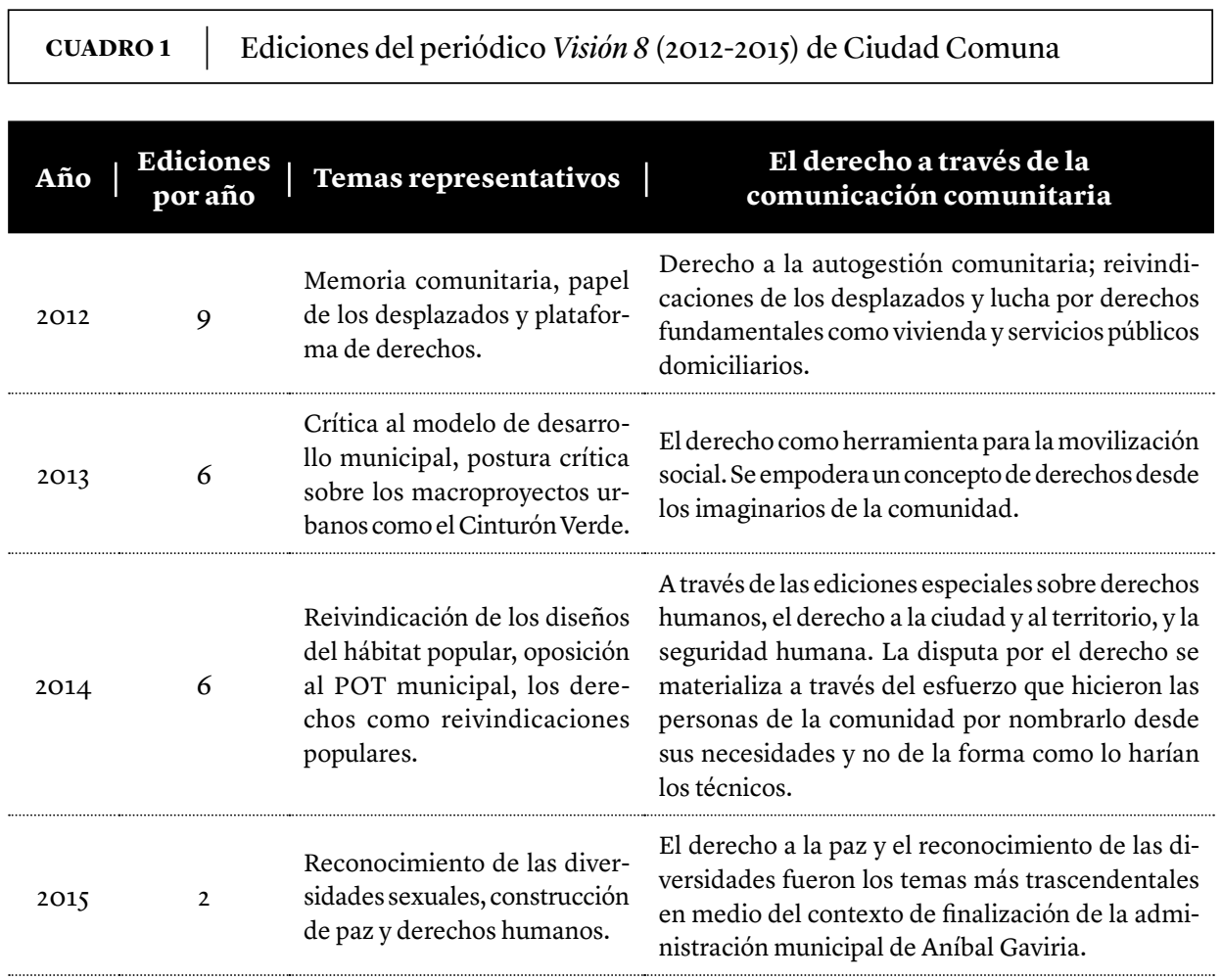

Fuente: elaboración propia a partir de la información del periódico comunitario.

CUADRO 2 $\mid$ Producciones audiovisuales 2012-2015

Producción audiovisual

Sobre la producción

Enlace web de acceso

Tiempo de duración

Año 2013

Video promocional de Ciudad Comuna con subtítulos

Explica la iniciativa comunicativa de Ciudad Comuna.

https://www.youtube.com/ watch?v=qeXuSSYuOK 4

3:51 min

Educación para la paz

Construcción del derecho a la paz desde el trabajo en algunos colegios de la Comuna 8.

https://www.youtube.com/ watch?v=KgSfNE_Zpog

Se denuncia la necesidad de apoyo

Cómo vemos el sector audiovisual en Ciudad Comuna al sector audiovisual y la construcción de medios críticos y puestos al servicio de las comunidades como materialización del derecho a la https://www.youtube.com/ watch? $\mathrm{v}=\mathrm{gmNbrZvSy}-\mathrm{c}$

2:06 min comunicación. 


\begin{tabular}{|c|c|c|c|}
\hline $\begin{array}{l}\text { Cinturón Verde } \\
\text { generando } \\
\text { desigualdad }\end{array}$ & $\begin{array}{l}\text { Se presentan las protestas por el } \\
\text { macroproyecto de ciudad, y se pro- } \\
\text { yectan la belleza y representaciones } \\
\text { en torno a los diseños del hábitat } \\
\text { popular, como elemento constitu- } \\
\text { tivo del derecho al territorio. }\end{array}$ & $\begin{array}{l}\text { https://www.youtube.com/ } \\
\text { watch?v=dKQ3QwXqoNw }\end{array}$ & $9: 40 \mathrm{~min}$ \\
\hline $\begin{array}{l}\text { Resistencias } \\
\text { diversas }\end{array}$ & $\begin{array}{l}\text { Se presentan las diversidades sexua- } \\
\text { les y la lucha de la población LGTBI } \\
\text { por sus derechos. }\end{array}$ & $\begin{array}{l}\text { https://www.youtube.com/ } \\
\text { watch?v=juYvX_3sLas }\end{array}$ & $6: 41 \mathrm{~min}$ \\
\hline $\begin{array}{l}\text { La ciudad detrás } \\
\text { de los espejos }\end{array}$ & $\begin{array}{l}\text { Medellín vista desde la pobreza. } \\
\text { Informalidad laboral y lucha de la } \\
\text { población por reivindicar su dere- } \\
\text { cho a vivir con dignidad. }\end{array}$ & $\begin{array}{l}\text { https://www.youtube.com/ } \\
\text { watch?v=Am-AQdIw_fE }\end{array}$ & $26: 44 \mathrm{~min}$ \\
\hline $\begin{array}{l}\text { Videoclip volvió la } \\
\text { guerra }\end{array}$ & $\begin{array}{l}\text { Desde el rap se narra la guerra de } \\
\text { los barrios y los anhelos del derecho } \\
\text { a la paz. }\end{array}$ & $\begin{array}{l}\text { https://www.youtube.com/ } \\
\text { watch?v=R8nJXhVAZk4 }\end{array}$ & 4:39 min \\
\hline $\begin{array}{l}\text { Por la vida } \\
\text { y la dignidad, } \\
\text { comunidades } \\
\text { en movilización }\end{array}$ & $\begin{array}{l}\text { Relata algunas experiencias de mo- } \\
\text { vilización social en busca de reivin- } \\
\text { dicar derechos como la vivienda y } \\
\text { los servicios públicos domiciliarios. }\end{array}$ & $\begin{array}{l}\text { https://www.youtube.com/ } \\
\text { watch?v=KK2az-zbOBo }\end{array}$ & 26:07 min \\
\hline $\begin{array}{l}\text { Documental } \\
\text { Repensando la } \\
\text { Seguridad }\end{array}$ & $\begin{array}{l}\text { Presenta las propuestas para repen- } \\
\text { sar la seguridad humana desde el } \\
\text { enfoque "desde abajo". }\end{array}$ & $\begin{array}{l}\text { https://www.youtube.com/ } \\
\text { watch?v=_JoAh5pYSaE }\end{array}$ & $27: 32 \mathrm{~min}$ \\
\hline
\end{tabular}

\section{Año 2014}

Relata la realidad social de la comuna, los procesos de lucha por un desarrollo desde abajo y con el enfoque de los derechos de la población.
Memoria social de la Comuna 8

El jardín
de las duda

https://www.youtube.com/ watch? $v=r B o o E x x K V B s$ 26:50 min

Uno de los documentales más representativos, donde se muestra la posición de la comunidad frente a las incertidumbres del proyecto urbano a ejecutarse en sus territorios. Un habitante de la comuna se pregunta: ¿acaso los campesinos no tenemos derecho a la ciudad?

\section{Mesa de \\ Desplazados \\ Comuna 8}

\begin{tabular}{ll} 
Pasos de Esperanza & $\begin{array}{l}\text { Crónicas de los niños habitantes de } \\
\text { los barrios informales. Se aprecia } \\
\text { el concepto del derecho a la ciudad } \\
\text { desde los más pequeños. }\end{array}$ \\
\hline $\begin{array}{l}\text { Dónde viviremos } \\
\text { mañana }\end{array} \ldots \ldots \ldots$
\end{tabular}

https://www.youtube.com/ watch? $\mathrm{v}=2 \mathrm{OU} 2 \mathrm{FMrxE} 8$

23:18 min

https://www.youtube.com/ watch?v=vrTFZIMOr4k 7:30 min

https://www.youtube.com/ watch? $\mathrm{v}=\mathrm{wg}-\mathrm{LYVxcH} 2 \mathrm{M}$ 13:20 min

https://www.youtube.com/ watch?v=vOS9ozInxaQ
23:18 $\min$ 
Recuento de la experiencia de la consulta popular en la que la pobla-

Video memoria consulta popular ción manifestó su rechazo al modelo de ordenamiento territorial impuesto por la administración, bajo la consigna de la protección de sus derechos. https://www.youtube.com/ watch?v=5lr7SGRe5AI

$5: 37 \mathrm{~min}$ https://www.youtube.com/
watch?v=qMZ34jyY-Uc

la frontera- Barrio

El Faro

Relatos desde

la frontera- Barrio

Las Golondrinas

Relatos desde

la frontera- Pinares

de Oriente

Relatos desde

la frontera- Altos

de la Torre

Relatos desde la

frontera- Barrio

Esfuerzos de Paz 1

Memoria de la exposición relatos

desde la frontera

Cartografía social comunitaria relatos desde la frontera

La serie muestra la historia de quienes habitan los territorios excluidos de los procesos de planeación de la Comuna 8. Se recupera parte de la memoria de estos barrios y sus habitantes afirman con convicción que tienen derecho a la ciudad. Los ejercicios cartográficos, la construcción colectiva y la puesta en común de los resultados fueron parte indispensable del proceso.

https://www.youtube.com/ watch?v=DMu16 7 DJOOo

3:04 min

https://www.youtube.com/ watch?v=RXY3JqtBuYw

2:42 min

https://www.youtube.com/ watch?v=uQ7OuItBXIg 2:49 $\min$

https://www.youtube.com/ watch?v=PDYJOJrmFnA

3:13 $\min$

https://www.youtube.com/ watch?v=QSWZTpRMyIo $7: 35 \mathrm{~min}$

https://www.youtube.com/ watch? $\mathrm{v}=\mathrm{IcnxAw5} \mathrm{VO}_{3} \mathrm{O}$

6:50 $\mathrm{min}$

La lucha de las personas de la comuna por reivindicar su derecho a tener el servicio de agua potable en los hogares.

Agua-cero

El diálogo de saberes como presupuesto para el diseño y planificación de territorios populares.

https://www.youtube.com/ watch?v=2JHeLVnUURY

23:44 min Saberes para hacer y transformar

Uno de los documentales más repre-

La dignidad que emerge de las laderas sentativos, en donde se muestran los procesos de movilización por los derechos en Medellín.

https://www.youtube.com/ watch?v=Rfh5TKIp8sA

$8: 27 \mathrm{~min}$

https://www.youtube.com/ watch?v=tnkiVsrxwso

26:03 $\min$

Convoca a la población para la de-

Videoclip Basta Ya fensa de los territorios, la vida digna y el derecho a la ciudad. https://www.youtube.com/ watch?v=YhoB452MnOs
2:05 $\mathrm{min}$ 


\begin{tabular}{|c|c|c|c|}
\hline \multicolumn{4}{|l|}{ Año 2015} \\
\hline Desalojo en 5 pasos & $\begin{array}{l}\text { Muestra los procesos de desalojo de } \\
\text { la población para la construcción de } \\
\text { megaproyectos urbanos. }\end{array}$ & $\begin{array}{l}\text { https://www.youtube.com/ } \\
\text { watch?v=pOb1oE4CQ1s }\end{array}$ & 2:12 min \\
\hline $\begin{array}{l}\text { Relatos desde la } \\
\text { frontera-La Sierra }\end{array}$ & $\begin{array}{l}\text { Las luchas cotidianas del barrio La } \\
\text { Sierra narradas por un niño. }\end{array}$ & $\begin{array}{l}\text { https://www.youtube.com/ } \\
\text { watch?v=4RgZTw6qRDo }\end{array}$ & 2:06 min \\
\hline $\begin{array}{l}\text { Revelando barrios. } \\
\text { La Sierra }\end{array}$ & \multirow{2}{*}{$\begin{array}{l}\text { Cuentan la historia del proyecto fo- } \\
\text { tográfico donde los habitantes más } \\
\text { pequeños de los barrios Villa Liliam, } \\
\text { Villa Turbay y La Sierra mostraron } \\
\text { imágenes de las dinámicas cotidia- } \\
\text { nas de sus territorios. }\end{array}$} & $\begin{array}{l}\text { https://www.youtube.com/ } \\
\text { watch?v=QaTV5pnotlg }\end{array}$ & $3: 02 \mathrm{~min}$ \\
\hline $\begin{array}{l}\text { Revelando barrios. } \\
\text { Villa Liliam y Villa } \\
\text { Turbay }\end{array}$ & & $\begin{array}{l}\text { https://www.youtube.com/ } \\
\text { watch? v=aONX8RZ_8K- } \\
\text { gyt=18s }\end{array}$ & 4:33 $\mathrm{min}$ \\
\hline
\end{tabular}

Fuente: Elaboración propia a partir de la información del canal de YouTube de Ciudad Comuna.

siguiendo metodologías participativas como fruto del trabajo desarrollado al interior de los semilleros de reportería escrita, audiovisual y la escuela de comunicaciones. Los contenidos generados no solo se difundieron de forma tradicional, sino que se utilizaron las redes sociales y la página web de la corporación.

Entre los años 2012 y 2015, en total se publicaron 23 ejemplares del periódico comunitario y se realizó un número significativo de producciones audiovisuales en las que participaron personas de todos los rangos etarios, activistas nacionales e internacionales, miembros de otras organizaciones sociales, miembros del sector académico, y otras fuerzas que mostraron la unión de sinergias en torno al logro de objetivos comunes; todo el contenido audiovisual fue publicado en el canal de YouTube de Ciudad Comuna. Como forma de acotar el estudio, solo se seleccionaron las producciones realizadas en la Comuna 8 de Medellín y en las cuales se observa un interés predominante por reivindicar las condiciones de vida en los barrios populares, resistir al modelo de ciudad que fue expuesto internacionalmente y trabajar por posicionar una comprensión del derecho a partir del discurso de la lucha por derechos en este contexto, como se detallará en el Cuadro 2. Se resalta del trabajo de Ciudad Comuna en lo audiovisual, las cápsulas, reportajes y el empleo de otros géneros periodísticos, como dos documentales muy relevantes en términos simbólicos, donde se cuenta la historia de movilización y lucha por los derechos de las poblaciones de la periferia de Medellín.

Para la parte final, se emplearon fichas analíticas que ayudaron a sistematizar y organizar la información de acuerdo con dos categorías centrales: 1) la lucha simbólica por el diseño de barrios dignos y el derecho popular, y 2) las imágenes del derecho a través de la comunicación comunitaria. Se hizo uso, además, de 
un diario de campo como medio para consignar las observaciones y reflexiones recogidas durante el trabajo empírico. La articulación entre estrategia, técnicas e instrumentos de investigación sirvió como medio de control y triangulación de la información recolectada.

\section{Una mirada al espacio local}

La Comuna 8 de Medellín (Villa Hermosa), lugar donde se encuentra ubicada Ciudad Comuna y desde donde los comunicadores comunitarios dirigen su trabajo, se encuentra situada en la parte centro-oriental de Medellín, rodeada por las comunas 3, 9 y 10, y el corregimiento de Santa Elena. Cuenta con una población aproximada de 139 493 habitantes (para el año 2019) y una extensión total de $57774 \mathrm{~km}^{2}$, conforme a lo proyectado en la actualización del último Plan de Ordenamiento Territorial (Alcaldía de Medellín, s. f.; Concejo de Medellín, 2014). Como correlato a estas cifras oficiales, las dinámicas territoriales de la población que habita en la comuna se distancian del régimen de representación creado por la visión oficial, puesto que las personas que habitan en las partes más altas han trazado las líneas de sus territorios, construido sus calles, espacios comunes y, de acuerdo con sus imaginarios e identidades, definieron los criterios a tener en cuenta para considerar cierto espacio territorial como barrio, más allá de lo impuesto por el Plan de Ordenamiento Territorial (POT), lo que da cuenta de una configuración comunitaria del territorio.

De esta manera, el establecimiento de la frontera político-administrativa como noción técnica y especializada a cargo del POT municipal, siguiendo a Serje (2011: 139-154), legitima un mito racionalizador que pretende organizar las actividades y comportamientos sociales a partir de la constitución de espacios fragmentados y jerarquizados para dar la idea de "un lugar para cada cosa y a cada cosa su lugar". En contraposición a esto, los complejos procesos sociales y territoriales apreciables en la Comuna 8 han dado cuenta de representaciones opuestas a la oficial, de tal suerte que, solo para hablar de cómo se entendía a un barrio por parte de la comunidad, se definieron 5 criterios para que se considerara a un sector como tal: 1) nombre socialmente compartido: toponimia; 2) puntos de referencia territoriales: naturales y artificiales; 3) proceso histórico de conformación urbana; 4) autonomía en la prestación de bienes y servicios básicos, y 5 ) dimensión territorial o poblacional (Alcaldía de Medellín; Corporación para la Paz y el Desarrollo Social [Corpades], 2007).

En consonancia con lo planteado, durante el trabajo de campo desarrollado por el autor, en diferentes ejercicios de cartografía social liderados por Ciudad Comuna, la comunidad hizo un trazado de los espacios habitados, de acuerdo con sus propias 
representaciones, yendo más allá de lo que para la oficialidad es definido como un sector, un asentamiento informal o ilegal, o un barrio. Este tipo de iniciativas autogestionadas y dirigidas por la misma comunidad constituyen una práctica contrahegemónica en donde los pobladores cuestionan las divisiones político administrativas de la ciudad y reconocen que los nuevos asentamientos surgidos, principalmente, debido a la recepción de población desplazada, han construido una identidad propia en contraposición a la del barrio receptor, lo que ocasiona que el mapa de la comuna de acuerdo con los imaginarios de los habitantes tenga más barrios, pero territorialmente sean más pequeños (Alcaldía de Medellín, Corpades, 2007).

La Figura 1 muestra unos diseños realizados por las personas de la comuna, en donde representan el hogar, el medio ambiente y la memoria como los referentes de la comuna, además de palabras como dignidad, resistencia, derechos y encuentro.

\section{FIGURA 1 Diseño de barrio digno por un miembro de la comunidad}

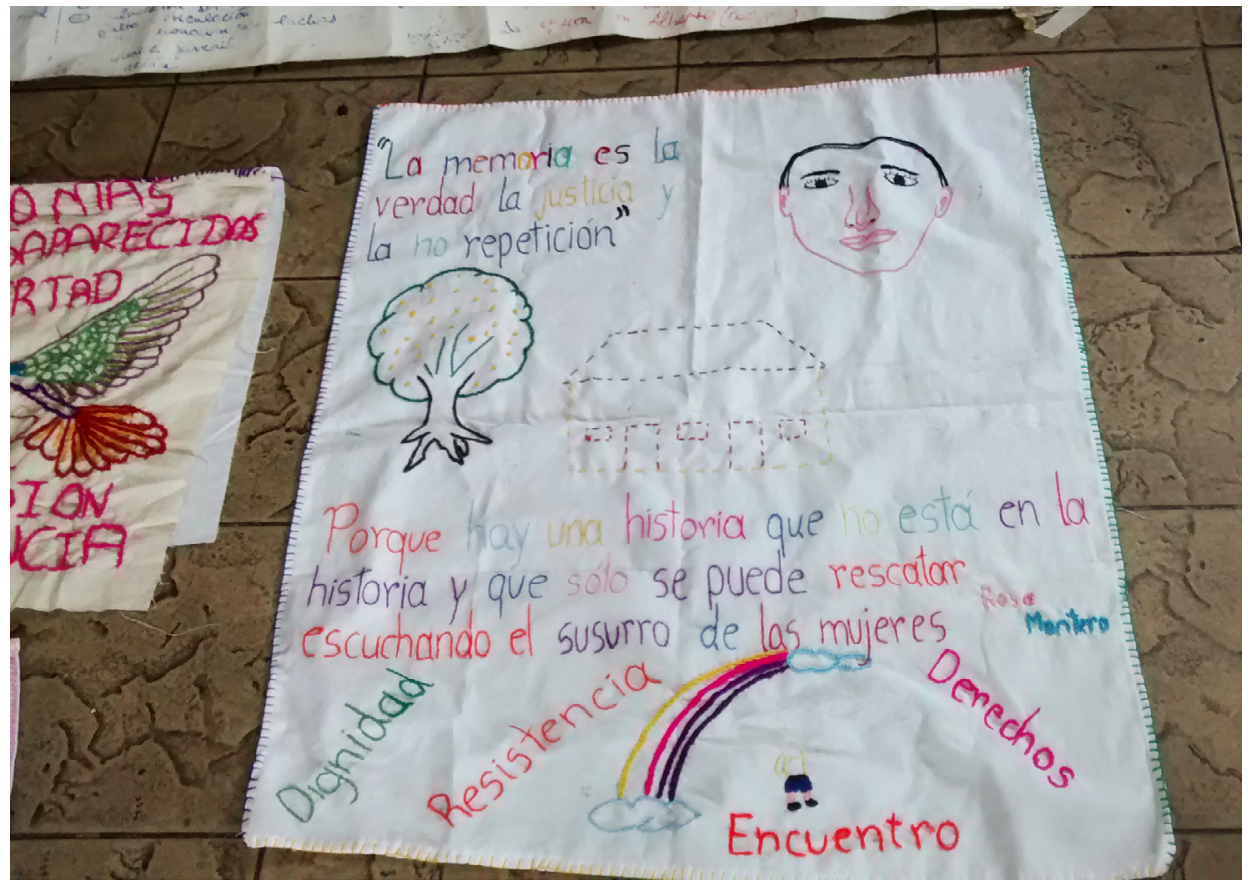




\section{La comunicación comunitaria y popular como fuente de alternativas}

La labor de Ciudad Comuna como organización de comunicaciones está relacionada con conceptos de comunicación de tipo comunitaria, popular, alternativa, para el cambio, entre otras. Si bien el abordaje de cada una de estas categorías cuenta con diversas discusiones teóricas, y se pueden advertir variadas relaciones entre ellas que hacen que en ocasiones sean imperceptibles sus fronteras - si es que existen-, en aras de buscar claridad conceptual se hará un acercamiento a las dos principales categorías trabajadas: lo popular y lo comunitario, con el fin de limitar el alcance que tienen cada una de ellas en este escrito, y para servir de marco de referencia al leer el sentido práctico que toman desde el hacer del colectivo de comunicaciones analizado.

De esta manera, apoyado en Pinto y Jiménez (2016) en su trabajo de reconstrucción del estado de la cuestión sobre la comunicación para el cambio social, se identifican como perspectivas emergentes de la comunicación a la popular, la comunitaria, la participativa, la ciudadana y la pública, incluyendo una noción que le hace justicia a la labor de los colectivos de base que trabajan en medios comunitarios como es la comunicación popular comunitaria, denominación que se ajusta más a los procesos y prácticas de Ciudad Comuna, como se precisará más adelante.

Sobre lo popular, existe un marco amplio de referencia que se identifica, en América Latina, con los considerados sin voz, es decir, los grupos excluidos de las posiciones de poder, congregados sobre la base social, como los campesinos, los indígenas, los trabajadores, los habitantes de las periferias de las ciudades, etc.; la praxis de estos grupos se dirige a la búsqueda por la emancipación y va en contra de lo hegemónico. La mirada sobre lo popular en el continente ha sido una cuestión estudiada, desde su amplitud, por una variedad de corrientes teóricas desde las que se resalta una fuerte influencia marxista que incluye estudios culturales, teología de la liberación, pedagogías emancipatorias, estudios decoloniales y poscoloniales, teorías de la dependencia, entre otras (Dussel, 1998; Freire, 2005; Mata, 2011; Navarro; Rodríguez, 2018).

Desde el fenómeno comunicativo, lo popular se vincula con las diferentes manifestaciones comunicativas de los grupos en mención, donde este elemento permite visibilizar sus propias realidades y, también, propiciar la participación activa en los asuntos que les interesan a todos, el reconocimiento de sus diversidades, sus prácticas culturales, sus reclamos dirigidos a transformar los contextos, entre otros (Pinto; Jiménez, 2016:20). En síntesis, la comunicación popular se asume como "una comunicación liberadora, transformadora, que tiene al pueblo como generador $\mathrm{y}$ protagonista" (Kaplún, 1985). 
En la misma dirección de lo planteado, la noción de comunidad en el continente no debe ser entendida como un concepto inmutable, sino que es la forma política de organización de los pueblos para resistir como sujetos colectivos, en tanto que "los pueblos crean/re-crean formas de relacionarse que llamamos comunidades" (Zibechi, 2017:32). Desde lo analítico, la comunicación comunitaria se circunscribe a una dimensión enfocada en lo local y con un fuerte arraigo territorial (Navarro; Rodríguez, 2018). Respecto a la dimensión mediática, se concibe a los medios comunitarios (radio, prensa, televisión, canales virtuales) como aquellos que están por fuera de la escena del control comercial de empresas privadas y que tampoco son de dominio estatal, usualmente vinculados con colectivos de base o procesos comunitarios, que tienen como una de sus funciones la de mediar y participar en diferentes experiencias que son consideradas relevantes en un contexto local (Pinto; Jiménez, 2016).

Generalmente, estos medios logran un grado de apropiación importante por parte de los miembros de una comunidad, hasta el punto de ser considerados como parte de un patrimonio común, pero no público. En igual medida, la gestión de los contenidos y la transmisión de sentidos son considerados importantes en la tarea de la educación, el fortalecimiento de los lazos vecinales y la construcción de sujetos críticos. De acuerdo con Pinto y Jiménez (2016:22), apoyados en Jankowski, se resaltan algunas características de los medios comunitarios: tienen como objetivo servir y empoderar a los miembros de una comunidad; la propiedad sobre estos radica en formas organizativas comunitarias como juntas de vecinos o los gobiernos de las localidades; los contenidos son diseñados de acuerdo a las necesidades comunitarias y no son dirigidos por profesionales; los medios de financiación son diversos, dentro de los que se incluyen mecanismos de autogestión, apoyo de gobiernos locales y pauta de algunos negocios, sin que esto signifique que los medios cambien su naturaleza para convertirse en entidades con ánimo de lucro.

Teniendo en cuenta los anteriores presupuestos, la comunicación popular comunitaria es una noción que hace referencia al trabajo comprometido, participativo y crítico de los sujetos populares en la búsqueda de construir alternativas comunicacionales que trasciendan el carácter instrumental de los medios tradicionales. Este esfuerzo se encamina a la construcción y fortalecimiento de la democracia y los vínculos comunitarios, mediante dinámicas de construcción colectiva, tanto de las agendas comunitarias como de los contenidos y las estrategias comunicacionales. Así, la comunicación comunitaria se convierte en propiciadora de una visión de desarrollo local, partiendo del lugar de enunciación de los sujetos que participan de este proceso, sus realidades y necesidades. Los medios comunitarios se convierten en los amplificadores de la voz de quienes no hacen parte de la narrativa de los medios de alto consumo, retratando la belleza y los detalles de la vida comunitaria, pero también 
sus problemáticas, resistencias, cotidianidades y diversidades. La comunicación popular comunitaria también propicia la educomunicación, lo que permite generar dinámicas de sensibilización para la movilización, el reconocimiento y diálogo de saberes populares, la formación política, la pedagogía de los derechos humanos, etc. (Pinto; Jiménez, 2016:30-31). De acuerdo con dos de los miembros de Ciudad Comuna, este es el enfoque de comunicaciones asumido por la corporación, en el entendido que

la organización ha logrado constituir y fortalecer un movimiento de comunicación comunitaria que con su labor periodística, investigativa, narrativa y de mediación social ha tejido lazos de unidad en las comunidades, en medio de las situaciones de conflicto social y armado, violencia estructural y desigualdades que padecen los territorios de la Comuna 8 de Medellín. (Gutiérrez; Jiménez, 2018: 2)

\section{La experiencia de Ciudad Comuna}

La Corporación para la Comunicación Ciudad Comuna es una organización popular que nació en el año 2009 a través del periódico comunitario Visión $8^{3}$, pero que con el tiempo consolidó otros procesos y colectivos, vinculados con la tarea de contribuir desde el trabajo de los medios locales en la defensa de los derechos de las comunidades más pobres de la Comuna 8. Esta iniciativa se posicionó como un proyecto comunitario que nació de la unión de jóvenes que buscaban reivindicar a los comunicadores de los barrios de la Comuna 8 como sujetos políticos que lideraban procesos de transformación social, y como una alternativa a través de la cual los sujetos populares pudieran construir sentidos comunes en torno a los asuntos que los impactaban, sus luchas y las trayectorias de los derechos humanos en la comuna, más allá de los relatos contados por la industria de los medios masivos de comunicación ${ }^{4}$.

Todos los contenidos generados por la corporación, al igual que sus procesos sociales, se realizaron acordes con metodologías participativas, empleando la pe-

3. Es preciso aclarar que dicho periódico surgió como una iniciativa popular desde 2006, y contaba con algunas ediciones antes de ser parte de Ciudad Comuna.

4. Ejemplo de esto es el reconocido documental La Sierra (2005), de Margarita Martínez y Dalton Scott, el cual fue grabado en un barrio popular de esta comuna, en medio de confrontaciones entre dos bloques paramilitares, y donde se muestran imágenes de la violencia que dominaba este espacio local, la pobreza, la falta de educación y la precariedad del Estado. Este tipo de producciones han sido resistidas por las mismas comunidades, que muestran que, más allá de esto, existen otro tipo de prácticas comunitarias en estos espacios. 
dagogía crítica y la investigación acción participativa (IAP), lo que permitió un constante diálogo de saberes en sus procesos: la escuela de comunicaciones con sus respectivos semilleros, el programa Revelando Barrios, los ejercicios de cartografía social, el Observatorio de derechos humanos y territorio, etc., al igual que el contenido de sus medios: Voces de la 8, una emisora virtual; Común Audiovisual, un colectivo audiovisual; el periódico Visión 8 , además del trabajo en redes sociales (Facebook, YouTube, Instagram, Flickr) y la página web.

FIGURA 2 Edición especial por el derecho al territorio

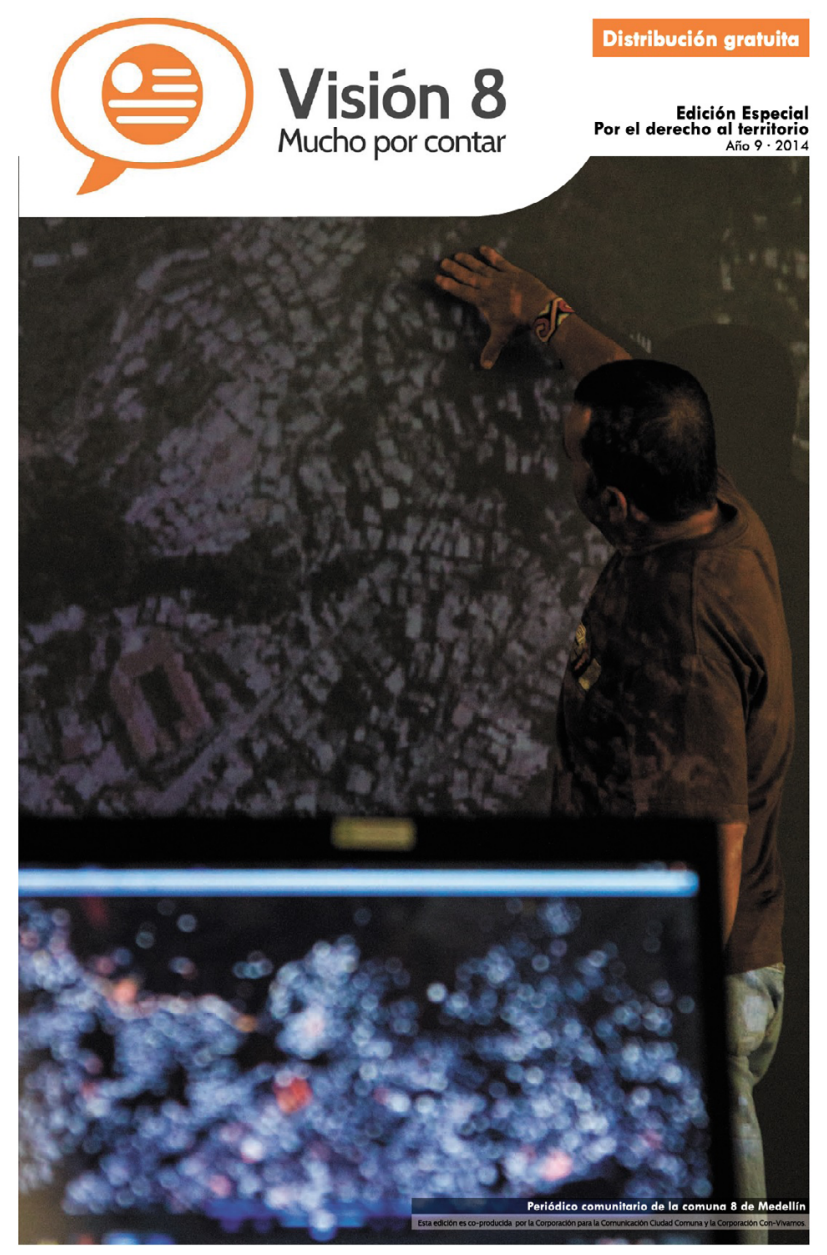

Fuente: Edición especial (2014). 
El lenguaje de los derechos de la comunidad fue la bandera transversal de las dinámicas comunicativas $\mathrm{y}$, debido a las situaciones propias del contexto que ya se han desarrollado, tuvo como resultado que entre los años 2013 y 2014 las publicaciones de Ciudad Comuna se concentraran en tres asuntos: la memoria, la ciudad y el territorio, abordados desde el enfoque de derechos. En 2015, se logró evidenciar un trabajo concentrado en las pedagogías críticas, la movilización social, el derecho a la paz y las acciones colectivas de impacto político.

Para resaltar algunas publicaciones representativas del periódico comunitario, en 2013 se dedicó una edición a la memoria; en 2014, una al derecho al territorio (Figura 2) y una edición especial: Aportes para la paz, los derechos humanos y la comunicación; además de diferentes artículos enfocados en el derecho a la ciudad y la crítica al modelo de ciudad con títulos como: "Medellín ciudad empantanada" (2012), y una edición destinada a los "Relatos de una ciudad de espejos y espejismos" (2013), entre otros.

Desde lo audiovisual, es relevante el esfuerzo realizado por mostrar los derechos insatisfechos de la población como la vivienda, los servicios públicos domiciliarios y la gestión del riesgo. Como producciones representativas, se encuentran: El jardín de dudas, La dignidad que emerge de las laderas, y Relatos desde la frontera: el derecho a la ciudad, una serie de cápsulas realizadas por Ciudad Comuna en coproducción con el Museo Casa de la Memoria, como ejemplos de luchas cotidianas de los habitantes de los barrios excluidos de la globalización neoliberal.

En los siguientes apartados se abordará el problema de la construcción colectiva y el papel de la comunicación comunitaria como herramienta de lucha y transformación social; para ello, se presentará el trabajo realizado por Ciudad Comuna en sus procesos revelando barrios, cartografía social, escuela de educación popular en comunicaciones, y el papel de la comunicación en la protesta social.

\section{Revelando barrios: otras imágenes de la vida en los barrios populares}

Revelando barrios es un programa de reportería gráfica que emergió del proceso de semillero itinerante de fotografía social de Ciudad Comuna. A través de este proceso, los niños y jóvenes de la localidad -desde su mirada sobre la ciudad-revelaron las imágenes invisibilizadas de los barrios populares, siendo este un ejercicio considerado por ellos como una práctica de resistencia y reivindicación del hábitat popular. Esta iniciativa tuvo origen en el año 2012, en el marco de la Escuela de Comunicación Comunitaria, y fue retomada en 2014, por parte del colectivo audiovisual como una 
forma de construir memoria, generar vínculos con el territorio y mostrar ideas sobre alternativas al desarrollo.

En total, en este proyecto participaron 160 niños y jóvenes entre 10 y 15 años, de El Pacífico, Altos de la Torre, El Faro, Las Golondrinas, Llanaditas, Pinares de Oriente, Villatina La Torre y Esfuerzos de Paz 1, barrios informales que se encuentran asentados sobre el borde urbano-rural de la Comuna 8 (Ciudad Comuna, 2015). El punto de partida del proyecto fue la resistencia al mapa político-administrativo oficial de la ciudad, con el objetivo de recuperar las imágenes y lugares de la comuna que sus habitantes consideraban representativos, como las casas de los vecinos, las calles y escalas autoconstruidas, la huerta comunitaria, la tienda de la esquina o aquellos sitios en los que se dialoga y se comparte entre amigos y vecinos.

A través de las imágenes que fueron el producto del trabajo con los niños, se exploraron otras formas de narrar lo cotidiano, se hicieron visibles las disputas en torno al desarrollo y ordenamiento territorial, y la historia de la ocupación de los bordes de la comuna, lo que, en palabras de la corporación, hizo evidente "el valor que los actores comunitarios y los procesos sociales le dan a su propio territorio y la resignificación que hacen del mismo, trascendiendo las fronteras del ordenamiento territorial establecido por el estado" (Ciudad Comuna, 2015: 148).

En este ejercicio, el discurso del derecho cumplió una función importante para la movilización y la resistencia. Los más pequeños hicieron un esfuerzo por nombrar el derecho, disputarse los sentidos que se dan dentro del campo jurídico y explicar el mismo desde las vivencias, experiencias, carencias y anhelos de este grupo poblacional. De esta manera, Revelando barrios "se ha consolidado entonces como un proceso que reivindica los derechos humanos, la seguridad y el derecho al territorio, en beneficio de la movilización social y prevención de la violencia" (Ciudad Comuna, s. f.).

\section{La cartografía comunitaria: el mapa como representación popular}

La cartografía, por mucho tiempo, fue el instrumento de los poderosos y de sus ejércitos para definir los límites de sus dominios. Los mapas, al establecer un orden de significación, son el resultado de un ejercicio de relaciones de poder. La geografía, desde su definición etimológica, es una marca sobre la tierra, un saber ligado al campo político y a la creación de una variedad de significaciones que hablan de la actuación de los sujetos sociales, de las apropiaciones materiales y simbólicas que estos realizan sobre el espacio (Porto-Gonçalves, 2001: 5-7). 
Durante el período 2012-2015, el trabajo de cartografía social liderado por Ciudad Comuna se convirtió en un ejercicio disruptivo que consistió no en las representaciones de las posesiones de los poderosos o del establecimiento de los límites administrativos, sino que fue una práctica de resistencia para poner en común aquellos anhelos, sueños, encuentros y desencuentros que se pueden hallar en los espacios habitados, también como un rechazo expreso del mapa oficial de la ciudad, al ser la imposición de un orden de significación de los poderes instituidos y no una verdadera construcción social.

Este proceso se abordó en tres etapas. La primera consistió en una dinámica de acumulación de metodologías, de experimentación y contacto con la comunidad. La segunda, en un ejercicio más de construcción de identidad de los barrios, de recoger memorias desde una dimensión política; es decir, sobre la organización social, los procesos de lucha por los derechos, en contra de la exclusión social y la guerra, escuchando las narrativas de la población desplazada -desde el destierro hasta llegar a ser constructores de ciudad-, las situaciones de vulneración de derechos, etc. La tercera fue un proceso de recolección de resultados obtenidos, sistematización y puesta en común de los mismos.

Dentro de las actividades que se desarrollaron en los ejercicios de cartografía social, se resaltan: talleres de cartografía barriales, realización de líneas de tiempo

FIGURA $3 \quad$ Trabajo de recuperación del derecho a la memoria

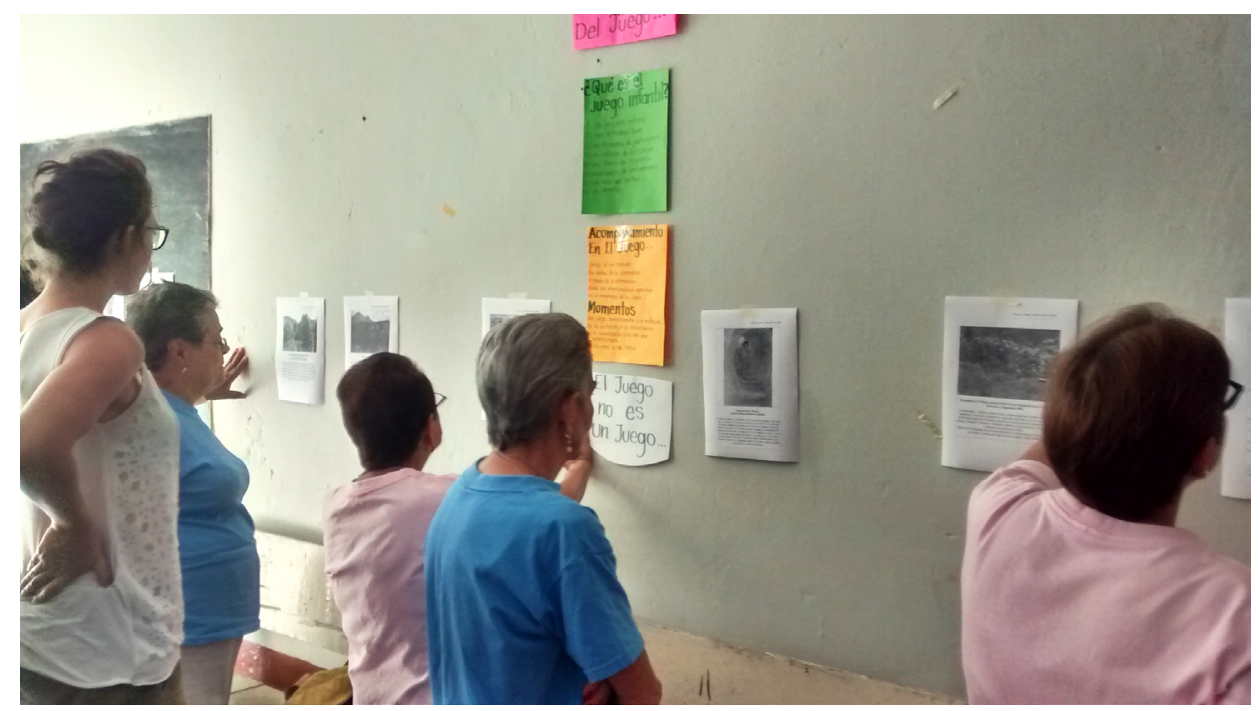

Fuente: archivo personal, parte del trabajo de campo. 
de la evolución de los barrios, entrevistas, recorridos de referenciación de los barrios, festival de la memoria (recuperación de archivos, fotos y vídeos sobre los barrios y la comunidad que se encontraban en manos particulares), ejercicios de sistematización y socialización con la comunidad, etc.

La cartografía social fue una herramienta útil para rastrear diversas lecturas territoriales, detallar las situaciones de los barrios, reconstruir historias y reivindicar saberes localizados. Frente al derecho, fue una forma que ingeniaron las personas de la comuna para representar su derecho al territorio, siendo la forma como los sujetos populares conciben vivir dignamente en sus territorios su principal consideración ontológica. Así, al ser gran parte de los habitantes de los asentamientos informales víctimas del desplazamiento forzado, desarraigados de sus prácticas y despojados de sus territorios, el derecho a gozar de un territorio en el que puedan desarrollar su vida y encontrarse con sus semejantes se convierte en una urgencia inaplazable, que no depende de ningún desarrollo legal o jurisprudencial, puesto que, sobre el particular, solo existe un instrumento, como el Convenio 169 de la Organización Internacional del Trabajo (OIT, 1989), que habla concretamente de territorios de los grupos étnicos como raizales, indígenas, palenqueros, pero que, como tal, no incluye referencias a los territorios populares urbanos.

FIGURA 4 $\quad$ Ejercicio de cartografía social






\section{La formación crítica en comunicaciones: una educación política}

La Escuela de Comunicación Comunitaria fue el proceso transversal a la formación de los comunicadores. A través de ella, se buscó incidir políticamente en la concienciación de los derechos de las personas que habitaban los bordes de la comuna y resaltar el papel de los comunicadores en este trabajo.

La formación política permitió crear, entre los participantes de la corporación, una sensibilidad especial que los involucró en las problemáticas de la comuna y los conectó con temas como los derechos humanos, el territorio y la memoria. Las habilidades comunicativas adquiridas por los participantes generaron los insumos necesarios para la creación de contenidos en los medios comunitarios y los diferentes los proyectos sociales de la corporación.

Este proceso, como práctica de resistencia, se edificó sobre la base de un proyecto educativo alternativo que perseguía la emancipación (Freire, 2005), es decir, la dignidad de la comunidad mediante la reivindicación de sus derechos. En este ejercicio, se emplearon diferentes herramientas como el periodismo y la investigación, resaltando, ante todo, los saberes contextualizados de los miembros de la comunidad. Como parte de él, tuvo crucial importancia la recolección de memorias de los procesos de autoconstrucción de los barrios populares y de las tradiciones campesinas que hacen parte de quienes habitan la periferia de la comuna.

Dentro de las dinámicas que se desarrollaron en el marco de la escuela, se resaltan los semilleros de narrativa de medios, donde se consolidaron el de radio comunitaria, documental social participativo y de reporterismo gráfico social. Además de esto, se desarrollaron círculos de estudio en los que se elaboró un proceso de repensar la investigación, actividades de periodismo comunitario y la construcción de narrativas con enfoque social, entre otras. Las herramientas metodológicas que se emplearon para estas finalidades fueron, principalmente: talleres lúdico-prácticos, mapas conceptuales y cartografías sociales, conversatorios para fomentar el diálogo, trabajo de campo para promover propuestas de investigación, construcción de proyectos colaborativos, memoria individual y colectiva (Confiar; Ciudad Comuna; Convivamos, 2015: 38-41).

\section{La comunicación comunitaria en la movilización social}

La labor del comunicador comunitario de Ciudad Comuna, además de la participación y acompañamiento de estas acciones, a través del video, la prensa, la fotografía y su postura crítica, hizo posible que se amplificara la voz y el reclamo por derechos 
de quienes han sido opacados por las estrategias de mercadeo de la ciudad, la publicidad institucional y las diferentes caras de Medellín que aprovecha la industria del turismo. En la Figura 5, se muestra la presencia vecinal y el acompañamiento de los medios de comunicación comunitarios en los procesos de incidencia política y movilización social en los cuales se denunció la exclusión de los territorios populares de la ciudad proyectada al mundo.

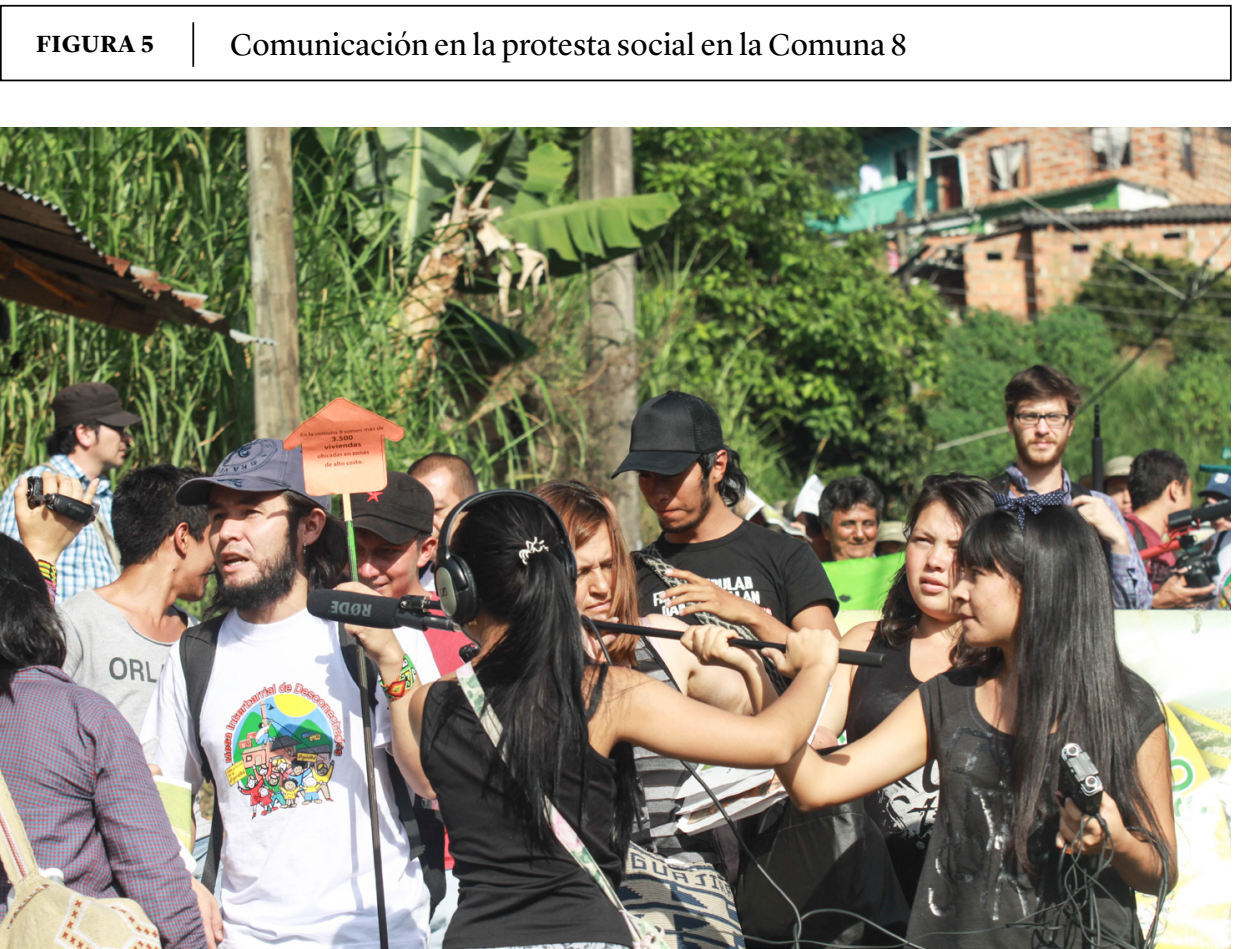

Foto: Ciudad Comuna, 2014.

\section{Conclusiones}

La labor de la comunicación comunitaria durante el período 2012-2015, en la periferia de la Comuna 8 de Medellín, trascendió el rol de medición entre unas fuentes y determinada audiencia, o de ser quien se centraba en hacer visibles las condiciones precarias en las que se habita en algunos barrios de la comuna. El comunicador popular, por su parte, logró adelantar un trabajo activo que marcó un compromiso por reivindicar los diseños cotidianos del hábitat popular, trabajar de manera colaborativa en los procesos de lucha y, principalmente, la promoción, educación y 
reivindicación de los derechos de los habitantes de la periferia de la ciudad. Sobre este particular, se logró evidenciar un claro interés por reconocer los diseños de barrios dignos como una práctica crítica localizada en la que se materializan principios de autonomía (Escobar, 2016), proyectos de vida dignos y otras formas en las que se aprecia la belleza del hábitat popular como ejemplo de un diseño desde el sur (Escobar, 2016). El comunicador comunitario no fue simplemente quien visibilizó o creó contenidos para nutrir los medios de comunicación, sino que fue quien se apropió del devenir de la comunidad, se unió, organizó, puso en común y realizó un trabajo desde diferentes dimensiones sociales, culturales, políticas y de pedagogía en derechos humanos.

El trabajo desde las comunicaciones sirvió de enlace o vehículo de demandas comunitarias donde participaron las reivindicaciones de los de grupos de diversidades sexuales, desplazados, afrodescendientes, indígenas, campesinos urbanos y demás grupos que habitan en la comuna. La participación de la comunidad a través de la comunicación comunitaria permitió desconcentrar los ejercicios de democracia local, reducidos, en la mayoría de ocasiones, a las Juntas Administradoras Locales y las Juntas de Acción Comunal.

Se destaca un trabajo especial con los niños y jóvenes, aspecto que permitió que estos, desde sus propias realidades, pudieran relatar y mostrar sus luchas, cotidianidades, expectativas, lazos afectivos y demás aspectos de la vida en los barrios, los cuales pasan desapercibidos para la industria mediática, que se ha dedicado a vender relatos de violencia y otras miradas excluyentes que reducen la ciudad a una mercancía intercambiable en un mercado global.

\section{Referencias}

Alcaldía de Medellín (2015). Informe final de gestión 2012-2015. Aníbal Gaviria Correa. Alcaldía de Medellín: Medellín.

Alcaldía de Medellín (s. f.). Perfil Demográfico 2016-2020 Comuna 8 Villa Hermosa. Recuperado de https://medellin.gov.co/irj/go/km/docs/pccdesign/SubportaldelCiudadano_2/ PlandeDesarrollo_0_17/IndicadoresyEstadsticas/Shared\%20Content/Documentos/ ProyeccionPoblacion2016-2020/Perfil\%20Demogr\%C3\%A1fico\%202016\%20-\%20 2020\%20Comuna\%2008_Villa\%20Hermosa.pdf

Alcaldía de Medellín; Área Metropolitana Valle de Aburrá; Centro de Estudios Urbanos y Ambientales (2011). Bio 2030, Plan director Medellín, Valle de Aburrá. Medellín: Mesa.

Alcaldía de Medellín; Corporación para la Paz y el Desarrollo Social (2007). Plan de desarrollo local Comuna 8 2008-2018: avances y retos de gestión. Alcaldía de Medellín: Medellín. 
Álvarez, Víctor (1996). Poblamiento y población en el Valle de Aburrá y Medellín, 1541-1951. En Historia de Medellín (pp. 57-84), coordinado por Jorge Orlando Melo. Bogotá: Suramericana de Seguros.

Betancur, María (2001). La globalidad de la producción: los impactos territoriales de las transformaciones productivas. En Globalización: cadenas productivas y redes de acción colectiva: reconfiguración territorial y nuevas formas de pobreza y riqueza en Medellín y el Valle de Aburrá (pp. 37-62). Bogotá: IPC/Tercer Mundo.

Bourdieu, Pierre (2000). Elementos para una sociología del campo jurídico. En La fuerza del derecho (pp. 153-216). Bogotá: Uniandes/Universidad Javeriana/Instituto Pensar/Siglo del Hombre.

Bourdieu, Pierre (2002). Pensamiento y acción. Buenos Aires: Libros del Zorzal.

Capella, Juan (2008). Fruta prohibida. Madrid: Trotta.

Capron, Guénola; González-Arellano, Salomón (2006). Las escalas de la segregación y de la fragmentación urbana. Trace, 49, 65-75.

Ciudad Comuna (2015). Memorias del proceso Semillero Itinerante de Fotografia Social: revelando barrios. Medellín: Ciudad Comuna.

Ciudad Comuna (s. f.). Historia. Recuperado de http://ciudadcomuna.org/ciudadcomuna/ historia-revelando-barrios.html

Concejo de Medellín (17 de diciembre de 2014). Acuerdo 48 de 2014. Gaceta Oficial, 21(4267). Recuperado de https://www.medellin.gov.co/normograma/docs/astrea/docs/a_ conmed_0048_2014.htm

Confiar; Ciudad Comuna; Convivamos (2015). La comunicación haciendo escuela: memorias del proceso de Escuela de Comunicación Comunitaria 2012-2013. Medellín: Cocotora.

Dávila, Luis (2016). Violencia urbana, conflicto y crimen en Medellín: una revisión de las publicaciones académicas al respecto. Criminalidad, 58(2), 107-121.

Dussel, Enrique (1998). Ética de la liberación en la edad de la globalización y de la exclusión. Valladolid: Trotta.

Echeverría, María Clara; Moreno, Cecilia; González, Luis Fernando; Mesa, Julio; Urrego, Gleidy (2016). Retos del hábitat: por la vida, la equidady los derechos territoriales. Medellín: CEHAP/UNAL.

Edición especial: por el derecho al territorio (2014). Visión 8. Recuperado de https://www. ciudadcomuna.org/ciudadcomuna/ediciones-anteriores-vision8/item/edicion-especialpor-el-derecho-al-territorio.html 
Escobar, Arturo (2016). Autonomía y diseño: la realización de lo comunal. Popayán: Universidad del Cauca.

Ferrajoli, Luigi (2018). Constitucionalismo más allá del Estado. Madrid: Trotta.

Fitzpatrick, Peter (2011). El derecho como resistencia: modernismo, imperialismo, legalismo. Bogotá: Siglo del Hombre/Universidad Libre de Colombia.

Franco, Vilma Liliana (2006). Poder regional y proyecto hegemónico: el caso de la ciudad metropolitana de Medellín y su entorno regional 1970-2000. Medellín: IPC.

Franco, Vilma Liliana (2011). Medellín: orden, desigualdad, fragilidad. Medellín: Corporación Jurídica Libertad-Sumapaz.

Freire, Paulo (2005). Pedagogía del oprimido. México: Siglo XXI.

Galeano, María Eumelia (2012). Estrategias de investigación social cualitativa: el giro en la mirada. Medellín: La Carreta.

Garcés, Ángela (2016). Prácticas en colectivos de comunicación caso Ciudad Comuna y Pasolini en Medellín. En Diálogo de saberes en comunicación: colectivos y academia (pp. 57-81), editado por Gladys Acosta; María Pinto y César Tapias. Medellín: Universidad de Medellín/CIESPAL.

Garcés, Ángela; Jiménez, Leonardo (2016). Comunicación para la movilización y el cambio social. Medellín: Universidad de Medellín/CIESPAL.

Garcés, Ángela; Jiménez, Leonardo (abril, 2017). Cartografias vitales: la producción del territorio y el derecho a la ciudad en las laderas de Medellín. Trabajo presentado en III Congreso Internacional de Estudios Urbanos, Quilmes, Argentina.

García-Villegas, Mauricio (2014). La eficacia simbólica del derecho. Bogotá: UNAL/IEPRI/ Debate.

Giraldo, Julián (2017). Medellín entre lo local y lo global: la resistencia popular y los derechos en la ciudad neoliberal. En Tensiones con los derechos humanos en el posacuerdo: luchas y resistencias por el derecho a la ciudady a los territorios (pp. 169-228). Medellín: IPC.

Giraldo, Julián (2020). Que alguien salve a Medellín: tras las falacias históricas de la "cultura del emprendimiento" en la ciudad. Medellín: Remington.

González, Luis Fernando (2007). Medellín, los orígenesy la transición a la modernidad:crecimiento y modelos urbanos, 1775-1932. Medellín: CEHAP/UNAL.

Grinberg, M. Simpson (1981). Comunicación alternativa y cambio social: América Latina. México: UNAM. 
Gutiérrez, Paola; Jiménez, Leonardo (2018). Comunicación Comunitaria y apropiación social de medios. La experiencia de Ciudad Comuna en Medellín. Recuperado de https://www. academia.edu/37270968/Comunicaci\%C3\%B3n_Comunitaria_y_Apropiaci\%C3\%B3n_ Social_de_Medios

Hart, Herbert (2004). El concepto del derecho. Buenos Aires: Abeledo-Perrot.

Harvey, David (2013). Ciudades rebeldes: del derecho a la ciudad a la revolución urbana. Madrid: Akal.

Harvey, David (2014). Diecisiete contradicciones y el fin del capitalismo. Quito: IAEN.

Kaplún, Mario (1985). El comunicador popular. Quito: CIESPAL.

Kavilando; Redipaz (2018). Victimas del desarrollo en Medellín: progreso y moradores en disputa. Medellín: Kavilando/Redipaz.

Kelsen, Hans (2009). Teoría pura del derecho. Buenos Aires: Eudeba.

Krohling, Cecilia; Tufte, Thomas; Vega, Jair (2011). Trazos de otra comunicación en América Latina. Barranquilla: Universidad del Norte.

Langford, Malcolm; Rodríguez, César; Rossi, Julieta (2017). La lucha por los derechos sociales. Los fallos judiciales y la disputa política por su cumplimiento. Bogotá: Dejusticia.

Lefebvre, Henri (1978). El derecho a la ciudad. Barcelona: Península.

Lemaitre, Julieta (2009). El derecho como conjuro:fetichismo legal, violenciay movimientossociales. Bogotá: Siglo del Hombre/Uniandes.

Lemaitre, Julieta (2011). ¿Constitución o barbarie? Cómo repensar el derecho en las zonas "sin ley”. En El derecho en América Latina. Un mapa para el pensamiento jurídico del siglo XXI (pp. 47-69), editado por César Rodríguez. Buenos Aires: Siglo XXI.

León, Osvaldo (1998). Iniciativas ciudadanas por el derecho a la comunicación. Chasqui, 64, 29-32.

Martín-Barbero, Jesús (1987). La comunicación desde la cultura. Crisis de lo nacional y emergencia de lo popular. Estudios sobre las Culturas Contemporáneas, 1(3), 45-69.

Mata, María (2011). Comunicación popular: continuidades, transformaciones y desafíos. Oficios Terrestres, 1(26). Recuperado de https://perio.unlp.edu.ar/ojs/index.php/oficioster restres/article/view/982/1031

Mata, María (2016). Comunicación y política: la imposibilidad de separarlas. América Latina en Movimiento, 513-514, 8-10. 
Mayor-Mora, Alberto (1989). Historia de la industria colombiana 1886-1930. En Nueva Historia de Colombia. Economía, café, industria (pp. 313-332), compilado por Álvaro Tirado. Bogotá: Planeta.

Montero, David; Domínguez, José (2020). Explorando el campo de conocimiento del video participativo. Un recorrido por las principales aportaciones teórico-prácticas. Revista Internacional de Comunicación y Desarrollo, 11, 92-108. https://doi.org/10.15304/ ricd.3.11.6345

Navarro, Felipe; Rodríguez, Paula (2018). Aproximaciones conceptuales: comunicación popular, comunicación comunitaria y comunicación alternativa. Commons, 7(2), 37-66. http://dx.doi.org/10.25267/COMMONS.2018.v7.i2.02

Nieto, Jaime (2013). Resistencia civil no armada: la voz y la fuga de las comunidades urbanas. Medellín: Hombre Nuevo/Universidad de Antioquia.

Organización Internacional del Trabajo (1989). Convenio 169. Sobre los pueblos indígenas y tribales. Recuperado de https://www.ilo.org/wcmsp5/groups/public/--americas/--ro-lima/ documents/publication/wcms_345065.pdf

Parra-Orozco, Juan (2009). Periodismo público-ciudadano sobre el ejercicio del derecho a la comunicación en las organizaciones sociales a través de las prácticas culturales. Mediaciones, 7(9), 49-59. https://doi.org/10.26620/uniminuto.mediaciones.7.9.2009.49-59

Personería de Medellín (2015). Informe sobre la situación de los derechos humanos en la ciudad de Medellín 2015. Medellín: Universidad de Medellín.

Pinto, María; Jiménez, Leonardo (2016). Estado de la cuestión en comunicación para el cambio. En Comunicación para la movilización y el cambio social (pp.13-53), coordinado por Ángela Garcés; Leonardo Jiménez. Medellín: Universidad de Medellín/Ciespal.

Porto-Gonçalves, Carlos Walter (2001). Geo-grafias: movimientossociales, nuevasterritorialidades y sustentabilidad. México: Siglo XXI.

Roy, Ananya (2013). Las metrópolis del siglo XXI. Nuevas geografías de la teoría. Andamios, 10(22), 149-181.

Ruíz, Adriana (2016). Derecho y violencia: de la teología política a la biopolítica. Medellín: UPB.

Samper, Jota; Ortiz, Catalina; Soto, Javier (2014). Repensando la informalidad: estrategias de co-producción del espacio urbano. Medellín: MIT/UNAL.

Santos, Boaventura (2005). El uso contra-hegemónico del derecho en la lucha por una globalización desde abajo. Anales de la Cátedra Francisco Suárez, 39, 363-420.

Santos, Boaventura (2009). Sociología jurídica crítica para un nuevo sentido común en el derecho. Bogotá: ILSA. 
Santos, Boaventura (2010). Refundación del Estado en América Latina: perspectivas desde una epistemología del sur. Lima: IIDS.

Santos, Boaventura (2014). Derechos humanos, democracia y desarrollo. Bogotá: Dejusticia.

Santos, Boaventura (2019). El pluriverso de los derechos humanos: la diversidad de las luchas por la dignidad. Madrid: Akal.

Santos, Boaventura; Rodríguez, César (2007). El derecho y la globalización desde abajo: hacia una legalidad cosmopolita. México: Anthropos.

Sassen, Saskia (2015). Expulsiones: brutalidady complejidad en la economía global. Madrid: Katz.

Serje, Margarita (2011). El revés de la nación: territorios salvajes, fronteras y tierras de nadie. Bogotá: Universidad de los Andes/CESO.

Serje, Margarita (2017). Fronteras y periferias en la historia del capitalismo: el caso de América Latina. Revista de Geografia Norte Grande, 66, 33-48.

Sierra, Jenny (2016). Medellín, ciudad neoliberal. Dinámicas socioespaciales en la formación de un hábitat urbano, 1970-2015 (Tesis de maestría). Universidad Nacional de Colombia, Facultad de Arquitectura, Maestría en Hábitat, Medellín.

Souza, Lourdes (2001). El uso alternativo del derecho: génesis y evolución en Italia, España y Brasil. Bogotá: ILSA/UNAL.

Tailor, Steven; Bogdan, Robert (1992). Introducción a los métodos cualitativos de investigación. Barcelona: Paidós.

Torres-Tovar, Carlos (2014). 7. ${ }^{\circ}$ Foro Urbano Mundial, Medellín, Colombia, 2014. Equidad urbana en el desarrollo-Ciudades para la vida. Bitácora Urbano Territorial, 24(1), 1-5.

Tribunal Superior del Distrito Judicial de Armenia (2020). Tribunal Superior del Distrito Judicial de Armenia Declara al Valle del Cócora como Sujeto de Derechos. Recuperado de http:// www.tribunalsuperiorarmenia.gov.co/tribunal-superior-del-distrito-judicial-de-armeniadeclara-al-valle-del-cocora-como-sujeto-de-derechos

Velandia, Rafael (2018). Medios de comunicación y su influencia en la punitividad de la política penal colombiana. Utopia y Praxis Latinoamericana, 1(1), 146-168. https://doi.org/10.5281/ zenodo.1462122

Zibechi, Raúl (2015). Medellín. La ladera grita, resiste y construye. Kavilando, 1(7), 39-46.

Zibechi, Raúl (2017). Movimientos sociales en América Latina. El mundo otro en movimiento. Bogotá: Desde abajo. 